\title{
INFLUENCE OF ELECTRODE SIZE AND GEOMETRY IN ELECTRO DISCHARGE DRILLING OF INCONEL 718
}

\begin{abstract}
Electro discharge machining (EDM) of thin deep features widens processing opportunities of difficult-to-cut materials, such as Ni-based alloys, towards attractive industrial applications. Conversely, the complex interaction between electrical, thermal and chemical phenomena in EDM thwarts process modeling and prediction. As a matter of fact, recent experimental discoveries encourage setting forth a new theory of discharge ignition in the gap, based on the role of debris, which lays foundations for a recursive mathematical model showing a chaotic evolution.

The paper reports on electro discharge drilling of small deep holes in Inconel 718. Process performances are measured with varying electrode size and geometry, attesting a pivotal effect of gap pollution on productivity and on the onset of a secondary detrimental removal of material by intergranular corrosion. All findings support the emerging model for discharge ignition via debris bridges and, most notably, debris chains are documented for the first time in the field of metals, second only to a previous case for a ceramic composite. On the whole, the paper provides conclusive validation of the role of debris in the ignition of discharges.
\end{abstract}

Keywords: electro discharge drilling; Inconel; electrode geometry; debris; discharge ignition

\section{NOMENCLATURE}

$\begin{array}{ll}I_{p} & \text { Peak current }(\mathrm{A}) \\ V_{a} & \text { Average voltage }(\mathrm{V}) \\ t_{o n} & \text { Pulse-on time }(\mu \mathrm{s}) \\ t_{\text {off }} & \text { Pulse-off time }(\mu \mathrm{s}) \\ \tau=t_{o n} /\left(t_{o n}+t_{o f f}\right) & \text { Duty ratio } \\ P=V_{a} \cdot I_{p} & \text { Pulse power }(\mathrm{W}) \\ E=V_{a} \cdot l_{p} \cdot t_{o n} & \text { Pulse energy }(\mathrm{mJ})\end{array}$




\section{INTRODUCTION}

Nickel-based alloys offer great resistance to corrosion and wear, together with capability to operate at high temperatures with limited decay in mechanical properties. They find successful applications in the automotive, aerospace, chemical, and energy fields [1]. On the other hand, they suffer from poor machinability for most cutting processes, both due to the mechanical properties (high hardness and toughness) and to the physical ones. As an example, low thermal conductivity of Inconel 718 hampers heat dissipation during tool-cutting processes [1]. Inconel 718 is a difficult-to-cut material, involving high tool wear, high risk of built-up edge, cost- and time-consuming machining operations [2]. Drilling is particularly critical, especially in the case of small holes and high aspect ratio, due to limitations as to the tool material and geometry. For such materials electro discharge machining (EDM) becomes competitive with respect to cutting processes or, if thin features are considered, it is actually the only choice and allows for applications beyond the capabilities of traditional machining operations [3-5]. The inherent low material removal rate of EDM processes, compared to traditional metal cutting, becomes negligible in the field of micro-dimensions. Attractive industrial applications are injection nozzles, air vents and cooling channels.

ED processes raise attention of many researchers. Several experimental studies address traditional wire EDM on Inconel alloys. Hewidy et al. [6] apply response surface methodology to develop experimental models for surface finish, material removal rate and electrode wear. Ramakrishnan and Karunamoorthy [7] move to a multi-objective optimization of the same responses by means of neural networks and Taguchi's parametric design. Newton et al. [8] focus on the recast layer, finding a depletion of chrome and nickel, versus an enrichment in brass migrated from the electrode, and a decrease in hardness with respect to the bulk material. They relate the recast layer thickness and roughness to energy per spark. Other experimental studies tackle ED processes applied to micro-features or small holes, providing data only for few work materials. A group from Jadavpur University addresses shallow microhole machining of Ti6AI4V alloy by a Taguchi approach: they develop mathematical models to represent the relationship of removal rate, tool wear and overcut to input parameters [9] and investigate the influence of different dielectrics [5]. Liu et al. [10] prove the feasibility of fabricating micro-holes in a high-nickel alloy with high magnetic permeability, showing that roughness can be improved by an in situ grind machining with a specific electrode. Kuppan et al. [1] report the results of deep hole drilling of Inconel 718, from a setup similar to the one used in this study, but with bigger diameter and lower aspect ratio. They quantify the dependence of material removal rate and surface roughness on peak current and pulse-on time by means of response surface methodology. Of the cited experimental studies, nearly all identify peak current as the main controlling factor, together with either pulse-on time or duty ratio. Only Newton et al. [8] attempt an energetic approach by evaluating the results versus the energy per spark. The authors of this paper believe in a similar view, embracing an interpretation of EDD in which pulse power is the ruling factor and discriminates distinct process regimes [11]. Yilmaz and Okka, in a noteworthy paper on EDD of Inconel 718 and Ti6AI4V [12], explore the influence of electrode geometry, i.e. single and multi-channel, finding a significant 
difference in material removal rate, to the advantage of the first. They ascribe the different efficiency to flushing conditions, specifically to the bigger channel size in multichannel electrodes, turning into quicker gap cleaning, lower discharge frequency and quicker cooling of the workpiece. They also observe comparatively finer surfaces for the holes drilled with multi-channel electrodes, but the result relies only on SEM imaging. Direct measurements of dielectric flow through the different electrodes and of surface roughness are lacking, but could be important for a better-grounded interpretation of the two results. This need is increased by recent theories on the role of debris in discharge ignition, which could revolutionize the former beliefs about the effect of high insulation in the gap.

In the traditionally accepted thermo-electrical theory, electrical discharges are initiated by ion action when the dielectric strength is overcome [4,13]. A plasma channel is thus generated, which melts material at the surface of each pole. When the pulsating current supply is turned off, the temperature suddenly drops, the plasma channel implodes and the molten material is flushed in the form of microscopic debris. Despite its diffusion, the above theory has been recently questioned on the basis of experimental observations collected and reviewed by Schumacher $[14,15]$. Ignition delay, gap widening, minimum current and influence of off-time are only the major hints that led to speculate a new model for discharge ignition, by evaporation of particle bridges. Schumacher infers that debris aligns under the influence of the electric field and the constriction of the gas bubbles; the bridges short-circuit the gap and vaporize by Joule heat, originating the plasma channel. This new model for the ignition of discharges complies with more recent observations of gas bubbles [16] and is gaining acceptance in literature [17]. The authors of the present paper embrace this theory, which found grounds recently, in the first evidence of the presence of debris bridges in ED drilling of a ceramic composite [18]. A speculative consequence of this new discharge model is that the long-accepted stochastic nature of ED processes has to be superseded by a chaotic character, being the development deterministic even if the outcome is unpredictable $[19,20,21]$. On a more practical level, neglecting transient phenomena in the gap can be deceptive. As one of many examples, the cited evidence for the persistence of gas bubbles casts doubts on the account of the effect of duty ratio on surface roughness in the study by Hewidy et al. [6]). Particularly in the case of small deep holes, where flushing conditions are critical, discharge ignition by debris bridges can be decisive to interpret the efficiency of electrodes having different size and channel geometry, which cause different debris concentrations in the gap.

EDD experiments are proposed in this paper with a threefold aim.

- To verify if bridge ignition can be proved not only for ceramic materials, but for metal alloys as well. A material having a high vaporizing temperature is chosen to this end.

- To verify if literature results, regarding the influence of electrode geometry and flushing conditions on EDD efficiency, need to be revised in the light of the new discharge model, and to include in the investigation the effects on surface roughness. 
- To interpret the above results in terms of pulse power, which can be a reliable descriptor of different discharge mechanisms since it includes voltage. If discharges occur by particles bridges, lower power regimes should be observed [21].

\section{MATERIALS AND METHODS}

Small-hole electro-drilling tests are performed on Inconel 718, using pure copper (99.9\% $\mathrm{Cu}$ ) electrodes. The experiments are conducted using a Sodick K1C, a high-speed small hole driller. The machine specifications are given in Table 1.

Table 1. Sodick $\mathrm{K} 1 \mathrm{C}$ working range

\begin{tabular}{ll}
\hline $\mathrm{X} ; \mathrm{Y} ; \mathrm{Z}$ Axis stroke $(\mathrm{mm})$ & $200 ; 300 ; 300$ \\
Electrode diameter $(\mathrm{mm})$ & 0.25 to 3.0 \\
Electrode rotation $(\mathrm{rpm})$ & 100 \\
Tool polarity & negative \\
\hline
\end{tabular}

Electrodes of three diameters are used: $0.25,0.4$ and $0.8 \mathrm{~mm}$. For the middle dimension, two different geometries are employed: single- and multi-channel, the latter with two cavities. Electrodes with $0.25 \mathrm{~mm}$ diameter are single-channel and $0.8 \mathrm{~mm}$ ones are multi-channel, as each is commercially available in only one geometry. Sections of the electrodes are shown in Figure 1.

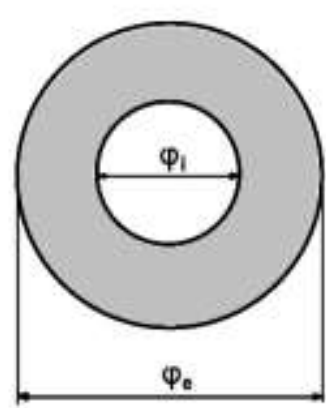

single-channel

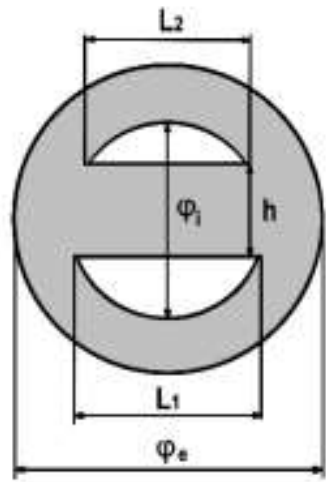

multi-channel

\begin{tabular}{ccccc} 
& \multicolumn{2}{c}{ single-channel } & \multicolumn{2}{c}{ multi-channel } \\
\hline$\varphi_{\text {e }}$ & 0.25 & 0.40 & 0.40 & 0.80 \\
$\varphi_{\text {I }}$ & 0.12 & 0.15 & 0.20 & 0.42 \\
L1 & & & 0.19 & 0.41 \\
L2 & & & 0.16 & 0.40 \\
h & & & 0.09 & 0.15 \\
\hline
\end{tabular}

Fig. 1 Sections and dimensions $(\mathrm{mm})$ of the electrodes.

Fresh VITOL-KS, a water-soluble commercial dielectric fluid, is pumped through the electrode's inner cavity. Electrical conductivity of the solution is measured at fixed intervals during the tests in a standard thermostated cell, with a Model 120 microprocessor conductivity meter. The cell constant is determined by measuring the conductivity of known solutions. Resistivity of the dielectric remains steady in the range 1.00-1.15 $\times 10^{3} \Omega \mathrm{m}$. The tests are performed in a temperature-controlled room to ensure thermal stability of the machine structure and a constant dielectric conductivity.

Through holes are drilled in $10 \mathrm{~mm}$ thick blocks of Inconel 718, whose composition is shown in Table 2, and physical-mechanical properties are reported by Ezugwu et al. [22]. 
Table 2. Chemical composition of Inconel 718 (weight \%)

\begin{tabular}{lllllll}
\hline Ni & Cr & Fe & Nb & Mo & Ti & Al \\
\hline $50.00-55.00$ & $17.00-21.00$ & Bal. & $4.75-5.50$ & $2.80-3.30$ & $0.65-1.15$ & $0.20-0.80$ \\
\hline
\end{tabular}

The EDD machine allows the variation of 4 input parameters: peak current $\left(I_{p}\right)$, pulse-on time $\left(t_{o n}\right)$, pulse-off time $\left(t_{\text {off }}\right)$ and servovoltage. Servovoltage is kept constant for all the tests at $75 \%$ of the maximum value. 15 discrete settings are possible for $t_{\text {on }}$ and $t_{\text {off }}$ (in the range $2-30 \mu \mathrm{s})$ and $I_{p}(2$ to $53 \mathrm{~A})$.

Previous studies, concerning EDD of $\mathrm{Al}_{2} \mathrm{O}_{3}-\mathrm{TiC}$ with $0.4 \mathrm{~mm}$ single-channel electrodes [11]Errore. II segnalibro non è definito., identified pulse power $(P)$ and duty ratio $\left(\tau=t_{\text {on }} /\left(t_{\text {on }}+t_{\text {off }}\right)\right)$ as primary factors. On this base, the experimental plan for this research is intended to be well distributed in the plane $(P, \tau)$, so that to cover the range of power between 500 and $2500 \mathrm{~W}$ and duty ratio from 0.25 and 0.9 . For ceramics, which are susceptible to thermal-shock cracking, relatively low power was used in [11] (180 to 910 $W)$. In the case of Inconel, the intent is to investigate a higher range, with benefits on MRR. Power, computed as peak current times average voltage, cannot be set directly on the machine but is obtained only during the operation by voltage reading. ED input parameters are chosen for $0.4 \mathrm{~mm}$ single-channel electrodes, based on previous experiments, as follows: $t_{\text {on }}$ between 6 and $30 \mu \mathrm{s}, t_{\text {off }}$ between 4 and $30 \mu \mathrm{s}, I_{p}$ between 13 and $53 \mathrm{~A}$. The experimental domain obtained for $0.4 \mathrm{~mm}$ single-channel electrodes is shown in Figure 2. For the other electrodes, the same input conditions (times and current) are adopted, which turn into different ranges of power that will be discussed in the results. Each test is repeated four times for each setting, using a new electrode for every series of four holes. Worn electrodes are measured and weighed. Holes are drilled on a grid with a step of $10 \mathrm{~mm}$ both in $\mathrm{X}$ and $\mathrm{Y}$ directions of the worktable.

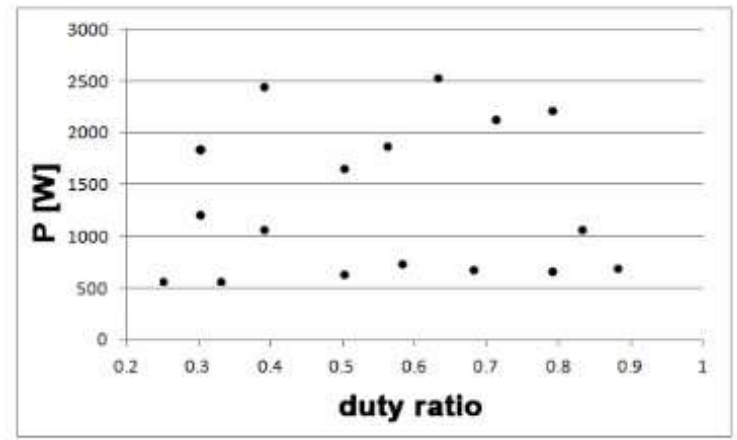

Fig. 2 Range of experimental setups in the plane $(P, \tau)$, for $0.4 \mathrm{~mm}$ single-channel electrodes

Additional tests are conducted for $0.4 \mathrm{~mm}$ electrodes with variations of the dielectric flow, in order to study the effect of different flushing efficiencies combined with different channel geometries. Flows through the electrodes are measured under standard delivery pressure ( $10 \mathrm{MPa})$, then pressure is varied to obtain the same flow through the single- and multi-channel electrodes. 
For each drilling operation, the following quantities are measured:

average voltage $V_{a}$, read on the machine voltmeter during operation;

drilling time, measured using an electronic timer $\left(t_{m}\right)$,

tool electrode wear, measured in terms of decrease in electrode length and converted into lost mass $\left(m_{E}\right)$;

workpiece lost mass $\left(m_{w}\right)$, measured by weighing the workpiece before and after drilling.

The performance criteria material removal rate (MRR) and electrode wear rate (EWR) are computed as in equations (1) and (2), respectively:

$$
\begin{aligned}
& M R R=\frac{m_{w}}{t_{m}} \quad[\mathrm{mg} / \mathrm{min}] \\
& E W R=\frac{m_{E}}{t_{m}} \quad[\mathrm{mg} / \mathrm{min}]
\end{aligned}
$$

In order to measure roughness of the electro-drilled surface, specimens are sectioned with a micro-cutter along a plane containing the axis of the holes. To preserve the inner surface, before cutting holes are filled by means of STC SHAPE-IN injection method. It consists in pouring bicomponent silicone material (polyvinyl siloxane), at room temperature and pressure. After curing, a silicone rubber is obtained that possesses high elasticity to allow extraction without damaging the surface.

Roughness is measured through a high resolution 3D chromatic confocal profilometer (ConScan - CSM Instruments) in accordance with ISO/DIS 25178-2 and ASME B46.1. An area of $0.2 \times 5 \mathrm{~mm}^{2}$ is scanned with the $0-300 \mu \mathrm{m}$ objective. Form removal and bylateral symmetric threshold filtering (for the removal of spikes) are applied on the maps. 3D surface roughness average $\left(S_{a}\right)$ is calculated on the maps and five profiles, parallel to the hole axis, are extracted to obtain 2D average roughness $R_{a}$. Surface homogeneity is checked in advance to validate the operation. $S_{a}$ provides a comprehensive measurement of surface morphology, but the more widespread linear parameter $R_{a}$ ensures a direct comparison with literature data.

The recast layer and the morphology of the hole inner surface are investigated by SEM.

Drilling debris is collected for 4 tests conducted with $0.8 \mathrm{~mm}$ electrodes: the conditions of minimum and maximum $M R R$, as well as minimum and maximum power are chosen. A multi-layer fabric is positioned under the workpiece during the operation. The filter is washed with acetone to remove the particles, which are then dried in air by acetone evaporation. Debris is observed by scanning electron microscope (SEM) with EDX (energy-dispersive X-ray) analysis. 


\section{RESULTS AND DISCUSSION}

For some experimental conditions, the $0.25 \mathrm{~mm}$ electrode wore out before completing the hole. The replacement of a new electrode would mostly change gap conditions, so results would not be comparable with other tests. Therefore, these tests are disregarded and results only include conditions that allowed to complete the drilling operation at once.

Results of all the tests are shown in Figures 3-5: points in the graphs represent the mean of four replications for each setup. For $0.4 \mathrm{~mm}$ electrodes, " $\mathrm{m}$ " and " $\mathrm{s}$ " in the legend label multi- and single-channel geometry, respectively.

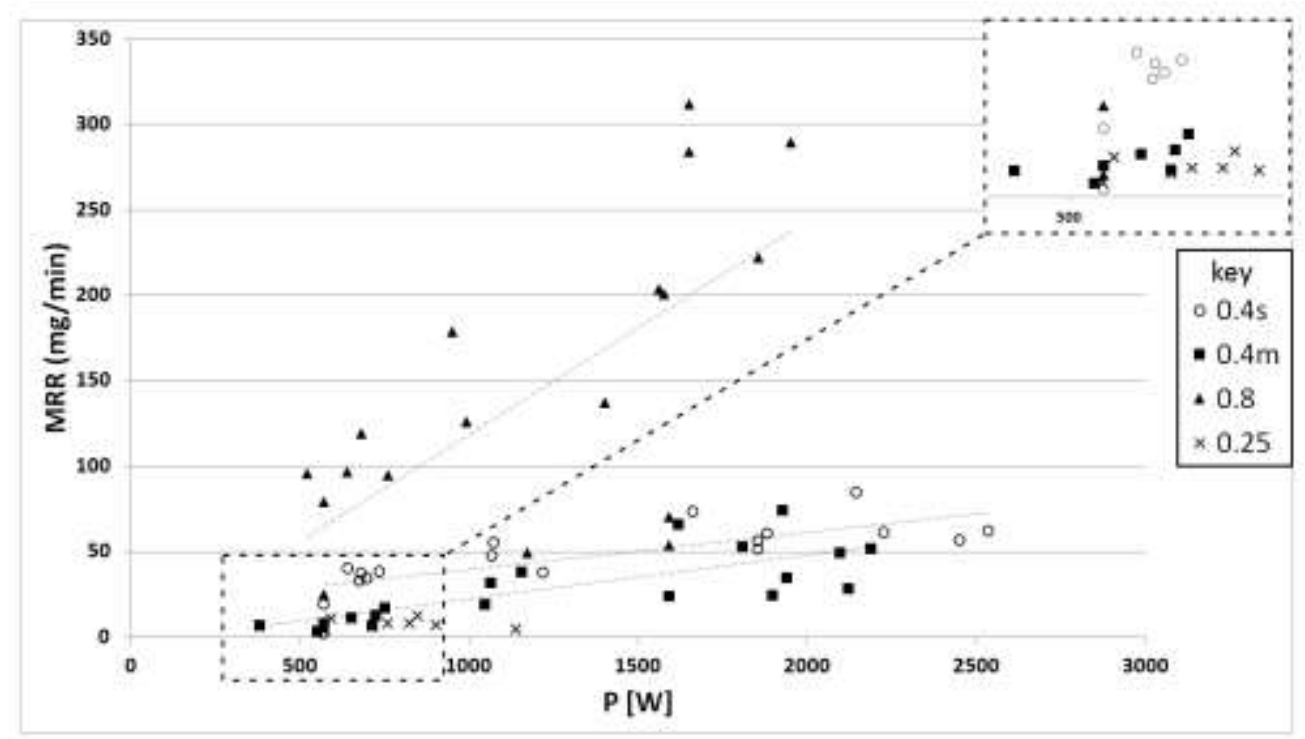

Fig. 3 Results of $M R R$ versus pulse power.

In this research, MRR for $0.8 \mathrm{~mm}$ holes varies in the range of 25.6 to $312.5 \mathrm{mg} / \mathrm{min}$, and increases with increasing power except for the test with the minimum pulse energy. A slighter variation but a similar trend can be observed for $0.4 \mathrm{~mm}$ diameter, with both single- and multi-channel electrodes, where $M R R$ is in the range 19 to $85 \mathrm{mg} / \mathrm{min}$ for most tests, except for the two performed with the lowest $E$. When pulse energy $E$ is below a threshold value of about 7 to $10 \mathrm{~mJ}$ for the 0.4 and $0.8 \mathrm{~mm}$ electrodes, the drilling speed undergoes an abrupt drop and $M R R$ decreases by five times. The latter seems to be the boundary of the machinability domain.

If the same process setup is compared for the different electrodes, MRR is generally higher for the bigger electrode. For $0.8 \mathrm{~mm}$ holes in particular, a set of tests where MRR is very high compared to the others can be observed. Multi-channel electrodes show to give lower MRR than single channel ones in $83 \%$ of tests. In almost all cases, if equal input parameters are used, single-channel geometry is related to higher pulse power and, consequently, greater MRR than obtained with multi-channel electrodes. Further investigation of this phenomenon is reported later in this section. 


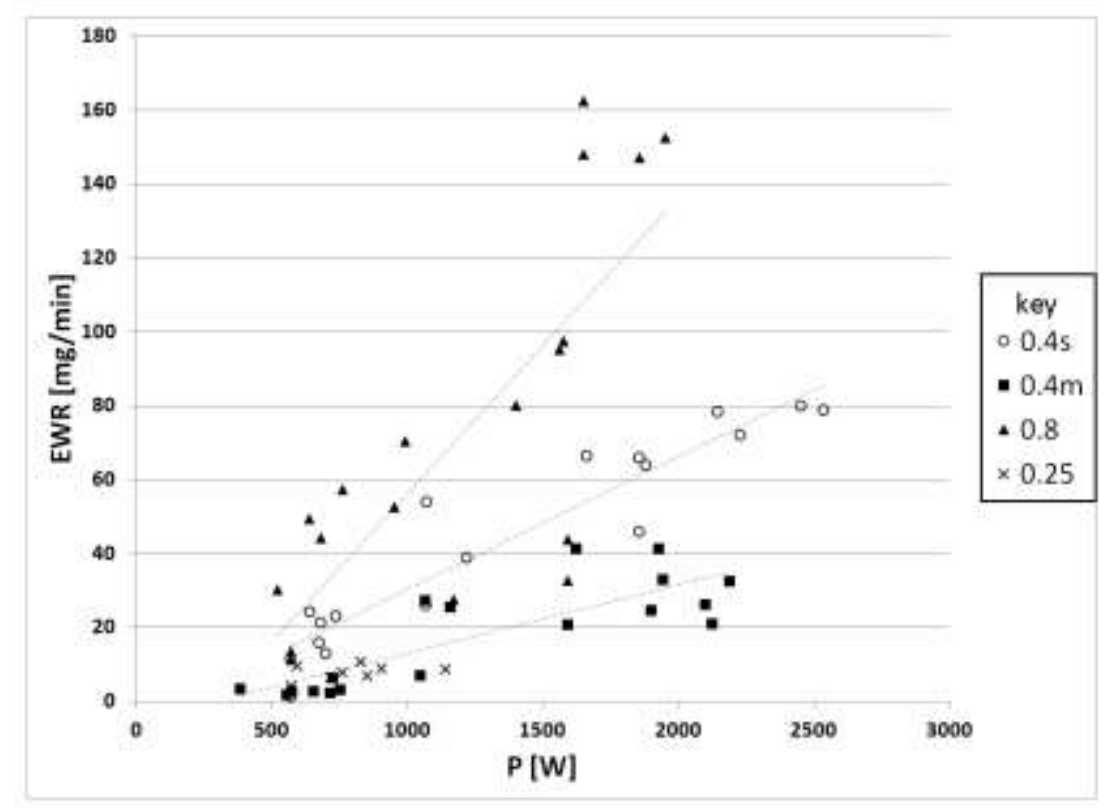

Fig. 4 Results of $E W R$ versus pulse power

EWR follows the same growing trend as MRR. For $0.8 \mathrm{~mm}$ electrodes it ranges between 11.6 and $162.8 \mathrm{mg} / \mathrm{min}$, and increases strongly with increasing power except for the test with the minimum pulse energy $(5.7 \mathrm{~mJ})$, in which EWR is $3.4 \mathrm{mg} / \mathrm{min}$. As for $M R R, 0.4$ $\mathrm{mm}$ electrodes show the same trend, in the range from 2.1 to $41.5 \mathrm{mg} / \mathrm{min}$ for multichannel electrodes, and up to $80 \mathrm{mg} / \mathrm{min}$ for single-channel geometry. Tool wear is particularly intense for the small electrodes in that it exceeds, in several cases, the relative amount of material machined away from the workpiece. This costuneffectiveness can be accepted for $0.25 \mathrm{~mm}$ holes, whose feasibility with as high an aspect ratio would not be unattainable by conventional processes.

If the two geometries with equal diameter are compared, multi-channel electrodes wear less quickly in all tests except one. 


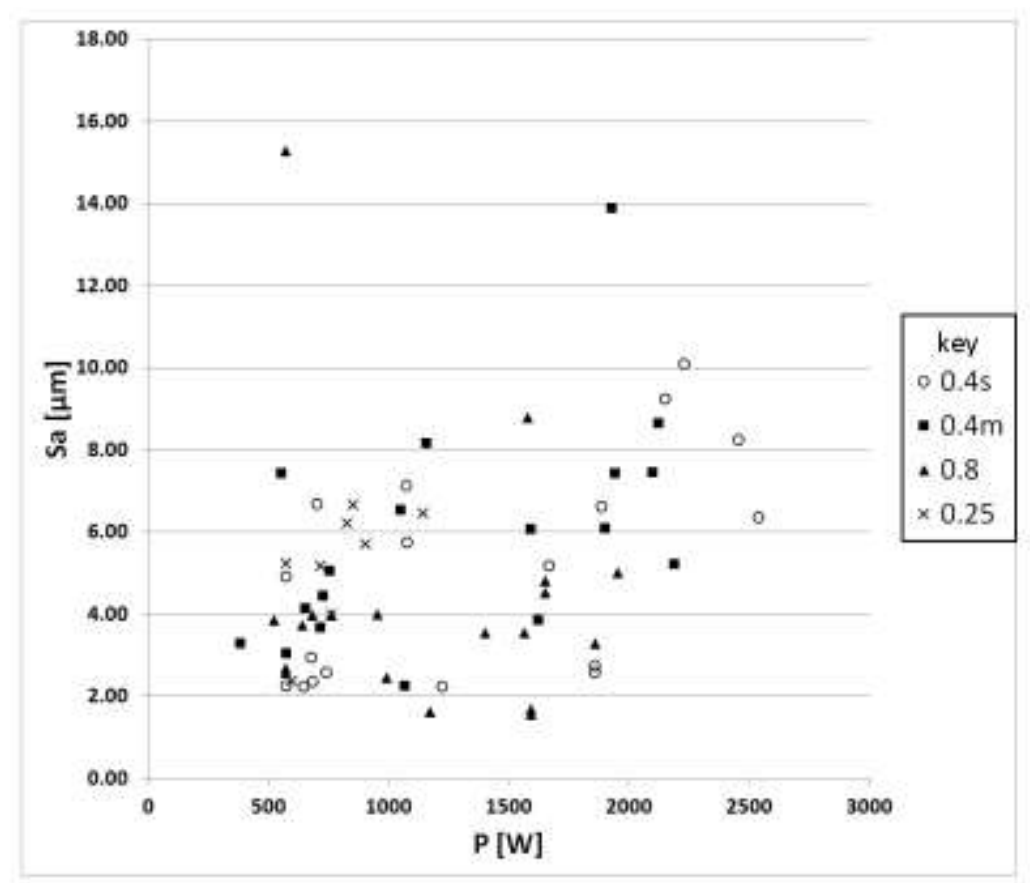

Fig. 5 Results of $S_{a}$ versus pulse power.

Surface roughness measured inside the holes does not show any clear trend with pulse power. Holes drilled slowly, in mild conditions, are almost as rough as those which much higher MRR. $S_{a}$ is between 2 and $10 \mu \mathrm{m}$ for all tests, except from two outsiders. When comparing different sizes and geometries of electrodes, a slight advantage in smoother finish is noticed for $0.8 \mathrm{~mm}$ over $0.4 \mathrm{~mm}$, and for single- over multi-channel geometry amongst the middle diameter. Specifically, $0.4 \mathrm{~s}$ electrodes give smoother holes than $0.4 \mathrm{~m}$ in $70 \%$ of tests performed with equal settings.

The effect of electrode geometry on the EDD process has been studied by Yilmaz and Okka [12], with an advantage for multi-channel electrodes. They ascribe performance differences to flushing conditions, on the unverified assumption of higher flow capacity across the multi-channel section. On the contrary, in our tests, if compared to singlechannel geometry, multi-channel electrodes give higher surface roughness and lower MRR, associated with wide fluctuations in machining time that may as much as double under unchanging conditions. Variability in machining time reflects a scattered operation that can be observed directly: these electrodes do not advance continuously, but they undergo frequent repositioning by the feedback control. Based on recent theories as to discharge mechanisms $[18,21]$, the described effect of electrode geometry is further investigated by focusing on the efficacy of debris removal by the dielectric flow.

Mass flow rate of the dielectric fluid across the different electrodes is measured at the standard pump pressure of $10 \mathrm{MPa}$, giving the results in Table 3.

Table 3. Mass flow rate of dielectric fluid across the different electrodes. Pump pressure of the Sodick K1C machine set at $10 \mathrm{MPa}$.

Electrode diameter/type Mass flow rate [g/min]




\begin{tabular}{ll}
\hline 0.25 & 4.0 \\
\hline $0.4 \mathrm{~m}$ & 12.8 \\
\hline $0.4 \mathrm{~s}$ & 25.0 \\
\hline 0.8 & 96.4 \\
\hline
\end{tabular}

For the geometries considered in this study, flow across the multi-channel electrode is nearly half of that through the single-channel one. Given these results, it is reasonable to suppose that multi-channel electrodes ensure lesser efficacy in the removal of debris from the gap, which can likely be the cause for the observed instability of the drilling process. To confirm the above hypothesis, the following test is performed: pump pressure is lowered until the mass flow rate through the single-channel electrode equals that across the multi-channel. The latter occurs for a pressure of 5.5 MPa. Then, two of the experimental setups in Figure 2 are repeated in this condition (three replications each). The immediate outcome is twitching of the electrode during the operation, resulting in fluctuating machining time. Results of machining time measured in these tests can be compared to the previous ones, with standard pump pressure, in Table 4 . Values of standard deviation in the table clearly point out that a more abundant flow of dielectric fluid favours stability of the electro discharge process. The differing outcomes obtained with the various electrodes can largely be attributed to the flow capacity. In this perspective, Yilmaz and Okka's assumption [12] appears prophetic, even if it leads to opposite findings to those reported here, which could leave the reader with the wish for a cross-check of experimental mass flow rates in the two cases.

Table 4. Machining time measured with varying pump pressure.

\begin{tabular}{|c|c|c|c|c|c|c|c|}
\hline \multirow[t]{4}{*}{$\begin{array}{c}t_{\text {on }} \\
{[\mu \mathrm{s}]}\end{array}$} & \multirow[t]{4}{*}{$\begin{array}{c}t_{\text {off }} \\
{[\mu \mathrm{s}]}\end{array}$} & \multirow[t]{4}{*}{$I_{p}[A]$} & \multirow[t]{4}{*}{$\tau$} & & \multicolumn{3}{|c|}{$\begin{array}{c}t_{m}[s] \\
\text { mean }(S D)\end{array}$} \\
\hline & & & & electrode type & $0.4 \mathrm{~s}$ & $0.4 \mathrm{~s}$ & $0.4 m$ \\
\hline & & & & pump pressure $[\mathrm{MPa}]$ & 5.5 & 10 & 10 \\
\hline & & & & mass flow rate $[\mathrm{g} / \mathrm{min}]$ & 12.8 & 25.0 & 12.8 \\
\hline 30 & 8 & 33 & 0.79 & & $28.7(9.2)$ & $20.7(1.4)$ & $40.7(13.7)$ \\
\hline 20 & 20 & 39 & 0.50 & & $29.8(6.9)$ & $14.0(0.9)$ & $19.4(3.1)$ \\
\hline
\end{tabular}

A more comprehensive evaluation of surface finish is possible by the direct SEM observation of the eroded surfaces, inside the holes, which integrates the results in Figure 5. Some examples are shown in Figure 6. Hole inner surfaces are covered with a recast layer where, in some cases, craters from single sparks are visible (Fig. 6a). In several tests, drilled surfaces are affected by intergranular corrosion, as shown in Figures $6 \mathrm{~b}$ ) and c). This phenomenon is visible for low values of pulse power, with greater incidence for electrodes of small diameter and for multi- rather than singlechannel geometry. Low pulse power often causes low $M R R$, meaning long machining time, during which the electro-chemical conditions in the gap cause corrosion at the grain boundary. In the wake of the above findings, the effect of electrode size and geometry is quite plain: electrodes with small diameter, or comparatively low flow capacity, lack in flushing effectiveness, which turns into discontinuous slow machining. 
The electrode is blocked inside the hole for a long time, because the main mechanism of material removal is hampered by low-voltage discharges in the presence of high debris pollution [21]. During this time interval, a secondary undesirable removal mechanism takes place, by electro-chemical corrosion. The latter is highly detrimental to parts' integrity, in that it can lead to premature corrosion or mechanical failure. Intergranular corrosion is not reported in traditional wire- or die-sinking- EDM of Inconel 718, where the geometries allow an easier gap flushing [8].
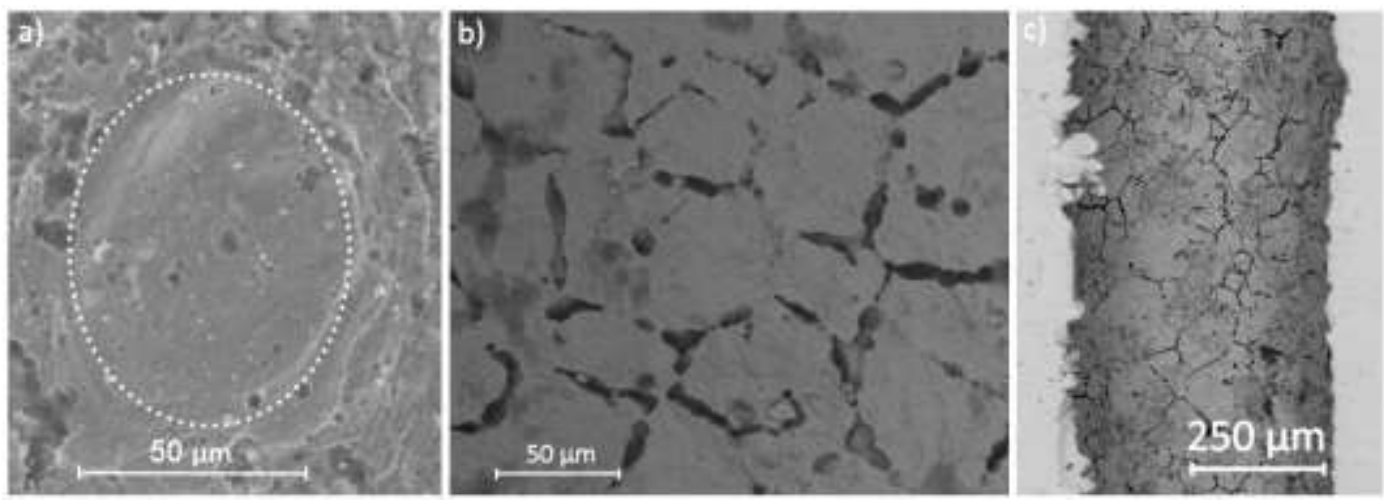

Fig. 6 SEM images of the surface inside the sectioned holes: a) electrode $0.8 \mathrm{~mm} ; t_{\text {on }} 30$ $\mu \mathrm{s}, t_{\text {off }} 6 \mu \mathrm{s}, I_{p} 19 \mathrm{~A}, P 950 \mathrm{~W}$. b) electrode $\left.0.8 \mathrm{~mm} ; t_{\text {on }} 14 \mu \mathrm{s}, t_{\text {off }} 28 \mu \mathrm{s}, I_{p} 19 \mathrm{~A}, P 570 \mathrm{~W} . \mathrm{c}\right)$ electrode $0.4 \mathrm{~m} ; t_{\text {on }} 28 \mu \mathrm{s}, t_{\text {off }} 4 \mu \mathrm{s}, I_{p} 13 \mathrm{~A}, P 650 \mathrm{~W}$

That efficacy of gap flushing is pivotal to the machining performances is consistent with the recent debate on the role of debris in the ignition of discharges in EDM processes $[18,21]$. The observation of debris has proven illuminating in the study of the discharge mechanisms [18]. The same approach is used here, with just as remarkable results. Figure 7 shows the first evidence of debris chains for a metal material, second only to the above example for a ceramic composite. SEM images clearly reveal necking between the particles, associated with a change in chemical composition due to diffusion phenomena, as reported in [18]. EDX analysis indicates a strong enrichment in $\mathrm{Nb}$ and $\mathrm{Ti}$ in the necks, together with high percentage of $\mathrm{Cr}$. 


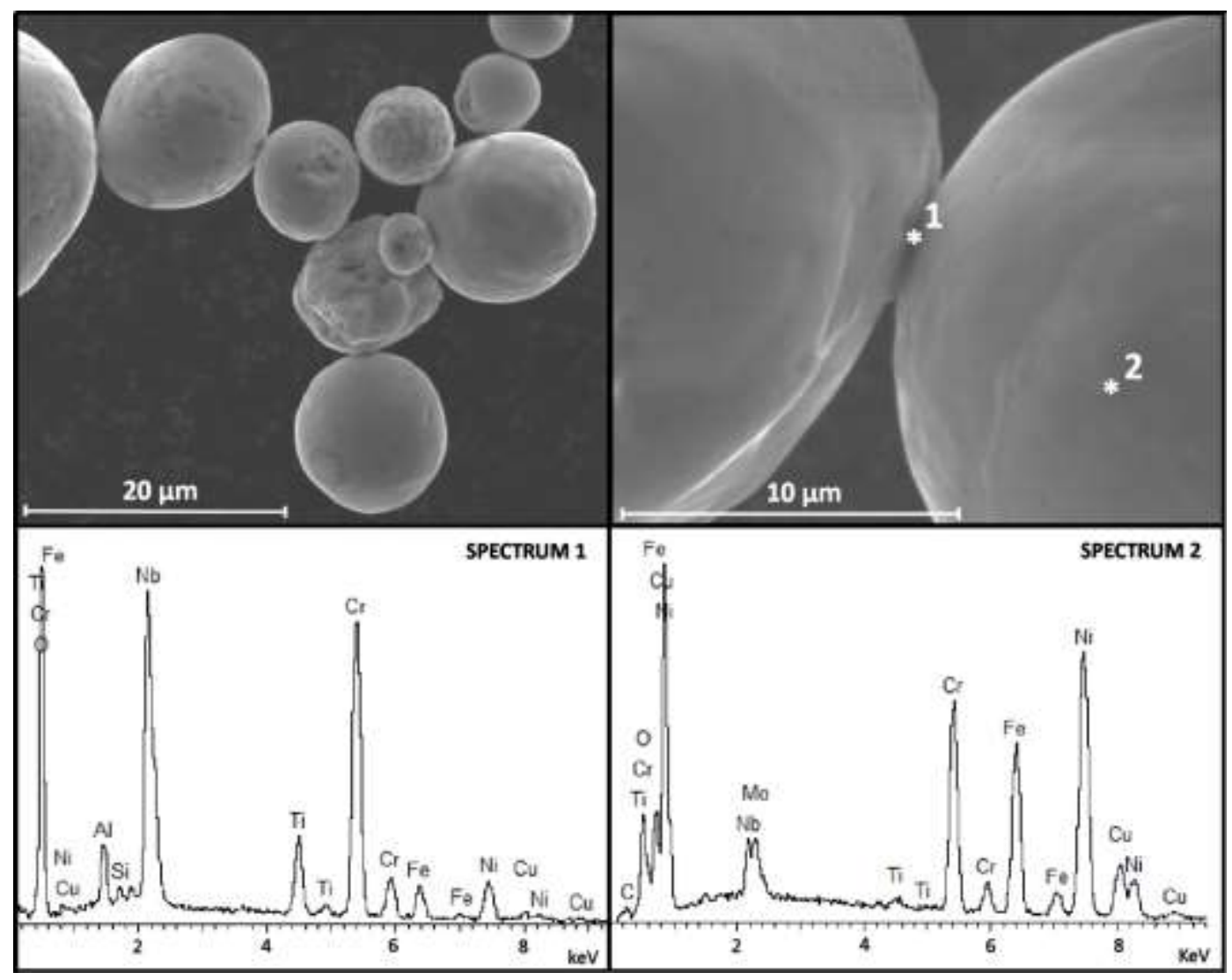

Fig. 7 SEM images of examples of debris chains and EDX measurement on the neck (spectrum 1) as compared with the average one (spectrum 2).

\section{CONCLUSIONS}

The paper addresses EDD of small deep holes in Inconel 718, in the light of recent theories on the role of debris in the ignition of discharges. Process performances, in terms of productivity, tool wear and surface roughness, are measured versus pulse power on varying electrode size and geometry, providing experimental validation that different behaviors are mostly related to the efficacy of gap flushing. The observed effects of gap pollution include intergranular corrosion of the drilled surface, taking place in the conditions of low process efficiency. The whole set of results fits into the emerging model for discharge ignition via debris bridges, which finds in this paper experimental proof by the observation of debris chains, documented for the first time in the field of metals.

Developments of this research will address the following corollaries of discharge ignition via debris bridges:

- The use of voltage feedback for gap control could to be rethought;

- Single-discharge studies could not be considered representative of industrial ED processes, single they neglect gap contamination;

- Resistivity of the dielectric fluid could loose relevance, as it would only concern the first machining steps. This would pave the way for the use of conductive particles in the dielectric, as in recent experiments with carbon nanotubes. 


\section{REFERENCES}

[1] Kuppan P, Rajadurai A, Narayanan S (2008) Influence of EDM process parameters in deep hole drilling of Inconel 718. Int J Adv Manuf Technol 38:74-84.

[2] Sharman ARC, Hughes JI, Ridgway K (2004) Workpiece surface integrity and tool life issues when turning Inconel 718 nickel based superalloy. Mach Sci Technol 8:399-414.

[3] Tan PC, Yeo SH (2008) Modelling of overlapping craters in micro-electrical discharge machining. J Phys D: Appl Phys 41:205302 (12 pp).

[4] Ho KH, Newman ST (2003) State of the art electrical discharge machining (EDM). Int J Mach Tools Manuf 43:1287-1300.

[5] Kibria G, Sarkar BR, Pradhan BB, Bhattacharyya B (2010) Comparative study of different dielectrics for micro-EDMperformance during microhole machining of Ti-6Al-4V alloy. Int J Adv Manuf Technol 48:557-570

[6] Hewidy MS, El-Taweel TA, El-Safty MF (2005) Modelling the machining parameters of wire electrical discharge machining of Inconel 601 using RSM. J Mater Process Technol 169:328-336.

[7] Ramakrishnan R, Karunamoorthy L (2008) Modeling and multi-response optimization of Inconel 718 on machining of CNC WEDM process. J Mater Process Technol 207(1-3):343-349.

[8] Newton TR, Melkote SN, Watkins TR, Trejo RM, Reister L (2009) Investigation of the effect of process parameters on the formation and characteristics of recast layer in wire-EDM of Inconel 718. Mat Sci Eng A 513-514:208-215.

[9] Pradhan BB, Masanta M, Sarkar BR, Bhattacharyya B (2009) Investigation of electro-discharge micro-machining of titanium super alloy, Int J Adv Manuf Technol 41:1094-1106.

[10] Liu H-S, Yan B-H, Huang F-Y, Qiu K-H (2005) A study on the characterization of high nickel alloy micro-holes using micro-EDM and their applications. J Mater Process Technol 169:418-426.

[11] Calignano F, Denti L, Bassoli E, Gatto A, luliano L (2013) Studies on electro discharge drilling of an Al2O3 -TiC composite. Int J Adv Manuf Technol 66(9):1757-1768.

[12] Yilmaz O, Okka MA (2010) Effect of single and multi-channel electrodes application on EDM fast hole drilling performance. Int J Adv Manuf Technol 51(1-4):185-194.

[13] Yeo SH, Kurnia W, Tan PC (2007) Electro-thermal modeling of anode and cathode in microEDM. J Phys D: Appl Phys 40:2513-2521.

[14] Schumacher BM (1990) About the Role of Debris in the Gap During Electrical Discharge Machining. CIRP Ann - Manuf Technol 39(1):197-199

[15] Schumacher B M (2004) After 60 years of EDM the discharge process remains still disputed. J Mater Process Technol 149(81-3):376-381.

[16] Schulze HP, Mecke K, Wollenberg G (2005) Influence of gas bubbles on electrical discharges in small working gaps. Int Conf Dielectr Liq 2005:63-66 
[17] Luo YF (1997) The dependence of interspace discharge transitivity upon the gap debris in precision electrodischarge machining. J Mater Process Technol 68(2):121-131

[18] Gatto A, Bassoli E, Denti L, Iuliano L (2013) Bridges of debris in the EDD process: going beyond the thermo-electrical model. J Mater Process Technol 213(3):349-360

[19] Han F, Kunieda M (2001) Chaos Found in Distribution of EDM Spark. Proc. of ISEM XIII, 185192.

[20] Kunieda M, Lauwers B, Rajurkar KP, Schumacher BM (2005) Advancing EDM through Fundamental Insight into the Process. CIRP Annals - Manufacturing Technology, 54-2:64-87.

[21] Gatto A, Sofroniou M, Spaletta G, Bassoli E (2015). On the chaotic nature of electrodischarge machining. Int J Adv Manuf Technol 79(5):985-996.

[22] Ezugwu EO, Fadare DA, Bonney J, Da Silva RB, Sales WF (2005) Modelling the correlation between cutting and process parameters in high-speed machining of Inconel 718 alloy using an artificial neural network. Int J Mach Tools Manuf 45(12-13):1375-1385.

[23] Prabhu S, Vinayagam BK (2008) A study on nano-surface generation in electric discharge machining process using multi-wall carbon nanotubes. Int J Nanoparticles 1(4):310-326.

[24] Mai C, Hocheng H, Huang S (2011) Advantages of carbon nanotubes in electrical discharge Machining. Int J Adv Manuf Technol 59:111-117.

[25] Izman S, Ghodsiyeh D, Hamed T, Rosliza R, Rezazadeh M (2012) Effects of Adding Multiwalled Carbon Nanotube into Dielectric when EDMing Titanium Alloy. Adv Mater Res (463464):1445-1449. 